\title{
Exposure Quality in Cognitive Behavioral Treatment for Youth Anxiety Disorders-Predictors and Associations with Outcomes
}

\author{
Krister W. Fjermestad (10 ${ }^{1} \cdot$ Nina Ditlefsen ${ }^{1} \cdot$ Marie H. Unsvåg ${ }^{1} \cdot$ Lars-Göran Öst $^{2} \cdot$ Odd E. Havik $^{3}$ • \\ Gro Janne Wergeland ${ }^{4,5}$
}

Accepted: 20 November 2021 / Published online: 10 December 2021

(c) The Author(s) 2021

\begin{abstract}
To optimize cognitive behavioral therapy (CBT) outcomes for anxiety disorders in youth, more knowledge is needed about how specific CBT components work. Exposure to feared situations is an effective CBT component. However, there is little observation-based empirical research on how exposure relates to outcomes and other clinical variables. In a randomized controlled community clinic trial for youth with anxiety disorders, observers reliably rated exposure quality for 68 youths aged 8 to 15 years based on 118 videotaped sessions. The treatment program was the manual-based FRIENDS program. Three exposure quality elements (preparation, post-processing, and parent contribution to exposure) were examined in relation to pre-treatment demographic and clinical variables, outcomes, and youth- and therapist-rated alliance using multilevel hierarchical regression models. The outcomes were diagnostic recovery, clinical severity and anxiety symptoms change from pre- to post-treatment and one-year follow-up, and treatment dropout. The results showed that parent contribution to exposure was higher for boys and younger children. Parent contribution to exposure, but no other exposure element, was associated with a larger likelihood of diagnostic recovery and larger clinical severity reduction at one-year follow-up. Exposure quality was unrelated to outcomes at post-treatment, dropout, or alliance. We conclude that enhancing parent contribution to exposure during treatment could improve long-term outcomes after CBT for youth anxiety disorders. Exposure elements should be observed in larger samples to further examine their potential role for CBT outcomes.
\end{abstract}

Keywords Cognitive behavioral therapy $\cdot \mathrm{CBT} \cdot$ Anxiety $\cdot$ Exposure $\cdot$ Youth $\cdot$ Intervention

\section{Highlights}

- We observed and coded exposure components in CBT for youth anxiety.

- Parent contribution to exposure was higher for boys and younger children.

- Parent contribution to exposure predicted diagnostic recovery one year after CBT.

- Exposure did not predict other outcomes, treatment dropout, or alliance.

Krister W. Fjermestad

kristefj@uio.no

1 Department of Psychology, University of Oslo, Oslo, Norway

2 Department of Psychology, Stockholm University, Stockholm, Sweden

3 Department of Clinical Psychology, University of Bergen, Bergen, Norway

4 Regional Centre for Child and Youth Mental Health and Child Welfare-Uni Research, Bergen, Norway

5 Haukeland University Hospital, Bergen, Norway
In the treatment of anxiety in youth, meta-analyses have demonstrated the efficacy of exposure-based therapy (e.g., Abramowitz et al., 2011; Olatunji et al., 2010; Wergeland et al., 2020). Exposure-based treatments, in which youth learn to face their fears through enduring, and not avoiding, situations with gradually increasing fear intensity, are associated with the largest effect sizes (Chorpita et al., 2002). Exposure alone can be as efficacious as exposure plus other procedures when treating anxiety disorders in youth (e.g., cognitive restructuring; Ale et al., 2015; Deacon \& Abramowitz, 2004). Despite the substantial evidence that exposure works, there are however concerns that exposure is underused in clinical practice. Community clinic therapists 
are three times more likely to report using cognitive restructuring than exposure (Hipol \& Deacon, 2013). In a survey of self-reported techniques used to treat anxiety disorders among therapists in outpatient clinics, exposure was ranked $15^{\text {th }}$ of 33 techniques (Whiteside et al., 2016). The underutilization of exposure in community clinical practice may be related to commonly held beliefs among clinicians, such as exposure may rupture the therapeutic alliance or lead to dropout (Peterman et al., 2015). Importantly, research suggests otherwise. There is no demonstrated link between exposure and attrition (Gryczkowski et al., 2013), and the child-therapist alliance was not reduced following exposure tasks in a CBT anxiety trial (Kendall et al., 2009). Nevertheless, the documented beliefs among clinicians in community practice may mean exposure elements are conducted differently outside efficacy settings. The current study aimed to examine therapists' use of exposure elements when cognitive behavioral therapy (CBT) was delivered in community clinics for youth with anxiety disorders. Our goals were to examine how much exposure elements were used, and if these elements were related to pre- and post-treatment variables, including outcomes.

The exposure component involves both cognitive and behavioral elements, and typically comprises four phases: (a) preparation and psychoeducation, (b) hierarchy development, (c) repeated gradual exposure with post-processing, and (d) generalization and maintenance (Seligman \& Ollendick, 2011). A handful of trials have explicitly examined associations between the exposure component in CBT for youth with anxiety disorders and outcomes. These trials have documented links between some elements of exposure and outcomes. Specifically, more coping behaviors during exposure (e.g., using breathing techniques), more postexposure processing, more rewards for conducting exposure tasks, and more therapist-reported time spent on exposure have all been associated with better outcomes (Hedtke et al., 2009; Peris et al., 2017; Peterman et al., 2016; Tiwari et al., 2013). On the other hand, more youth safety-seeking behaviors during exposure (e.g., checking for exits) has been associated with poorer outcomes (Hedtke et al., 2009). Other elements of exposure, such as preparation, difficulty level, compliance, and mastery, have been found to be unrelated to outcomes (Peris et al., 2017; Peterman et al., 2016).

This initial evidence provides the field with some direction about how to tailor exposure tasks to optimize CBT outcomes. However, this evidence-base is limited by few studies, all of which have been based on the Coping Cat program (Hedtke et al., 2009; Peris et al., 2017; Peterman et al., 2016; Tiwari et al., 2013) and conducted in efficacy settings (i.e., university-led intervention sites with specialized therapists). It is important to study if these previous findings also apply for other treatment programs conducted in community settings with regular (i.e., not specialized) therapists. Thus, there is a need for studies examining exposure elements using different programs delivered in different settings. The current study used the 10-session FRIENDS for life manual ( $4^{\text {th }}$ edition, Barrett, 2004). Considerable evidence has accumulated over the last decades demonstrating the effectiveness of FRIENDS as both treatment and prevention for youth anxiety (see Briesch et al., 2010; for review). However, the FRIENDS program comprises four exposure sessions which are mainly focusing on preparing and processing exposure to be conducted outside the treatment sessions (e.g., by youth and parents as homework tasks) through the use of "coping step plans". This is in contrast to the Coping Cat program, in which six of 16 sessions (Kendall \& Hedtke, 2006) comprise exposure, including in-session exposure. It is therefore important to examine the exposure elements in FRIENDS, which is a much-used intervention program (e.g., Briesch et al., 2010; Lowry-Webster et al., 2003). The lack of knowledge about exposure quality and its' relation to outcomes for programs with other exposure elements (e.g., amount of in-session, details of instructions, degree of session focus) than in the Coping Cat program represents a gap in the field and is the focus of the present study.

Herein, we build on the findings of Tiwari et al. (2013), who developed an observer-rated exposure quality rating form adapted for the Coping Cat program. On this rating form, independent observers scored the frequency and duration of four exposure elements. The elements were introduction (e.g., rapport-building), preparation (e.g., role-play), processing (e.g., evaluate exposure performance), and closing (e.g., reward for effort). Coders also rated the global quality of exposure preparation and processing. Tiwari et al. (2013) examined if these exposure elements were related to several outcomes. i.e., clinician-rated clinical severity, parent-rated general mental health symptoms for the youth, and youthrated anxiety symptoms. The study provided important knowledge about the exposure component in this setting, documenting initial evidence that post-exposure processing, rewards for exposure, and more exposure homework were associated with better clinician-rated outcomes, but not with parent- and youth-reported outcomes. Preparation for exposure was not related to any outcomes (Tiwari et al., 2013). The authors concluded that future studies should further examine exposure elements in CBT for youth anxiety, and specifically that the studies should examine the role of youth age, parental involvement, and youth-therapist alliance. The current study responds to this call.

Herein, we define exposure quality as the level (i.e., magnitude) of exposure-related components observed in randomly selected treatment sessions. To further extend the field's knowledge about the exposure component when CBT is delivered outside university clinics, we examined exposure quality beyond potential associations with 
outcomes. First, we examined if pre-treatment variables were associated with exposure quality because it is important to identify factors that may enhance or reduce exposure quality. This is because of the associations between exposure and outcomes. In a recent review, Plaisted et al. (2021) aimed to identify factors that enhance the effects of exposure across anxiety disorders in youth. The authors identified that less use of safety behaviors, parent and therapist discouragement of avoidance, and use of homework seemed to enhance the effects of exposure for outcomes. However, not one significant finding was replicated across the 29 studies examined in Plaisted et al. (2021). This led the authors to conclude that more studies are needed on predictors of exposure components. Another reason to include pre-treatment predictors of exposure is the evidence that exposure is less used in community settings compared to university-based settings (Hipol \& Deacon 2013; Whiteside et al., 2016).

The pre-treatment variables we examined were youth age and gender, primary anxiety diagnosis, and symptom severity. Youth age was included because exposure quality may be influenced by developmental stages (Digiuseppe et al., 1996). A recent review of 29 exposure studies with youth concluded that more knowledge is needed about how exposure works in various developmental stages because the role of age has not been examined (Plaisted et al., 2021). Youth gender was included because girls tend to have more anxiety than boys, both in terms of disorders and symptoms (Arendt et al. 2014; Beesdo et al., 2009). Furthermore, therapist and parents may also treat boys and girls differently in anxiety-provoking situations based on typical gender stereotypes (e.g., be "tougher" with boys; Morawska, 2020). This may also mean that exposure works differently for girls and boys. Type of anxiety diagnosis was included as it may be easier to adapt exposure tasks for more specific fears (e.g., separation anxiety; social phobia) than for more general fears (e.g., generalized anxiety disorder). There is some evidence that the exposure component may play out differently with different anxiety disorders. For example, Peterman et al. (2016) found that greater initial fear was associated with lower anxiety severity at one-year follow-up for youth with separation anxiety and/or social anxiety disorder, but not for youth with generalized anxiety disorder. Finally, pre-treatment symptoms were included as exposure tasks may be more challenging with youth with higher symptom levels. For example, Peterman et al. (2016) showed that initial fear levels were associated with exposure-outcome relations.

Second, we examined if exposure quality was associated with outcomes. We included the following outcomes: diagnostic recovery, and change in clinical severity and anxiety symptoms. Dropout was added as an additional outcome since this is a common concern in community treatment
(Wergeland et al., 2015). Third, we examined if exposure quality was associated with the alliance, defined as the collaborative bond between clients and therapists (Shirk and Saiz, 1992). We included this aim because of claims that community clinicians fear that conducting exposure tasks will diminish the alliance (Peterman et al., 2015). Although there is no evidence that this is the case from university trials (Kendall et al., 2009), it is important to examine if such associations can be identified in community trials.

Thus, our first study question was: Is youth age and gender, primary anxiety disorder, and/or initial anxiety levels associated with exposure quality? Due to limited previous data, this study question was explored openly without a priori hypotheses. Our second research question was: Is exposure quality associated with outcomes, measured at post-treatment and one-year follow-up? Based on previous findings, we expected more post-exposure processing to predict better outcomes (Tiwari et al., 2013). Our final research question was: Is exposure quality associated with youth- and/or therapist-rated alliance? Based on existing evidence, we expected higher exposure quality to be associated with a higher alliance (Kendall et al., 2009).

\section{Methods}

\section{Trial Setting}

The sample for the current study is drawn from a completed randomized controlled trial (RCT) comparing individual and group CBT to waitlist (Wergeland et al., 2014). The trial was conducted across seven community clinics, covering urban and rural areas in Western Norway. The main results from the trial were that both the individual and group CBT formats outperformed the waitlist condition. There was no difference in response or remission rates between the individual and the group format (Wergeland et al., 2014). The current study uses data from the individual FRIENDS arm of the main trial. Intent-to-treat analyses of participants in the individual CBT (ICBT) arm showed that $35.2 \%$ had lost their primary anxiety disorder at posttreatment, which had increased to $46.2 \%$ at one-year followup (Wergeland et al., 2014). Clinical severity and anxiety symptoms were significantly reduced from pre-treatment to post-treatment and one-year follow-up, with medium effect sizes (Wergeland et al., 2014).

\section{Participants}

\section{Youth Participants}

The sample for the current study comprised 68 youths ( $M$ age $=11.1, S D=2.1,45.5 \%$ girls, $89.4 \%$ European-White) 
from the ICBT arm of the original RCT. Participants were included if at least one videotaped exposure session, i.e., session 6-10, was available. The sample represents $72.5 \%$ of the complete ICBT sample. Participants with missing tapes had either dropped out of treatment before the onset of exposure sessions $(n=13)$ or had missing tapes for technical reasons $(n=12)$. Two of the 68 participants with available videotapes dropped out after the exposure sessions. These two cases were included in the analyses although they did not have post-treatment outcome data. All participants were regular referrals to community clinics. Inclusion criteria were at least one of the following primary anxiety diagnoses: separation anxiety disorder (SAD, $37.9 \%$ ), social phobia (SOP, 39.4\%), or generalized anxiety disorder (GAD, 22.7\%). The majority of participants $(63.6 \%)$ had at least one co-morbid inclusion anxiety diagnosis. Anxiety diagnoses were assessed with the Anxiety Disorders Interview Schedule (ADIS; Silverman \& Albano, 1996; see measures section). Exclusion criteria were primary severe conduct disorder, psychosis, and/or severe learning difficulties. Co-morbid non-anxiety disorders were assessed with the Development and Wellbeing Assessment (DAWBA; Goodman et al., 2000). Family social class was measured with the Health Behaviour in School-Aged Children Family Affluence Scale (Currie et al., 2008) and rated as high for $30.3 \%$, middle for $48.5 \%$, low for $12.1 \%$, and was missing for $9.1 \%$.

\section{Therapist Participants}

Therapists $(n=17, M$ age $=49.8$ years; $S D=9.4 ; 93.3 \%$ female; $100.0 \%$ European-White) were employed at the community clinics. Eleven were psychologists (64.7\%), five (29.4\%) were clinical pedagogues (masters of education with additional clinical training), and one (5.9\%) was a clinical social worker (a bachelor-level degree with additional clinical training). Therapists had a mean of 11.8 years of clinical experience $(S D=6.3$; range 3 to 27). Five therapists had completed a formal two-year post-graduation CBT training. The other therapists had little or no formal training in CBT prior to the study.

\section{Treatment}

The treatment program followed the FRIENDS for life manual $4^{\text {th }}$ edition (Barrett, 2004; Barrett \& Ryan, 2004). The program is conducted in 10 one-hour sessions with two one-hour booster sessions. The program has evidenced efficacy (Liber et al., 2008; Shortt et al., 2001) and effectiveness (Wergeland et al., 2014). There are two separate versions of the program adjusted for developmental level. Participants aged 8-12 years received the child version and participants aged 12-15 years received the adolescent version. The 12-year-olds could be assigned to either age group, based on clinicians' assessment of their maturity level.

The exposure and problem-solving component is introduced in session 5 (child version) or 6 (adolescent version) and is focused on breaking down problems and/or feared stimuli into manageable steps for gradual practice/exposure. It is emphasized that the step plans should lead to a clearly defined aim (e.g., give a presentation, use public transport). The work on participants' coping step plans continues throughout the program as homework tasks that are reviewed in every session. In the subsequent sessions, management and progress of the coping step plans are further addressed through the introduction of how peers and role models can support you with the progression of the plan(s), how to use relaxation and cognitive restructuring tasks to enhance coping with exposure steps, and how to reward oneself for efforts.

Parents join the last $15 \mathrm{~min}$ of each session plus one complete session about role models/support teams (session 6 in the child version and session 7 in the adolescent version). In addition, there are two separate parent group sessions during the program focused on psychoeducation about childhood anxiety and parental strategies for anxiety management.

All treatment sessions were videotaped; $20 \%$ were randomly selected for adherence and competence ratings using the Competence and Adherence Scale for Cognitive Behavioral Therapy (CAS-CBT) instrument (Bjaastad et al., 2016). The therapists demonstrated adequate adherence and competence (see Wergeland et al., 2014).

\section{Measures}

\section{Anxiety Disorders Interview Schedule/Clinical Severity Ratings}

(ADIS-C/P/CSR; Silverman \& Albano, 1996) child and parent versions were used to determine diagnostic status. The ADIS-C/P covers a range of various anxiety disorders. We used the sections for the diagnoses included in the current study (i.e., SAD, SOP, and GAD). For those participants who endorsed more than one anxiety disorder, the diagnosis with the highest CSR was counted as the youth's primary diagnosis. The CSR is a 0 (no impact) to 8 (severe impact) scale concerning the degree of functional impairment due to anxiety in terms of social, academic, and family functioning. The CSR is scored by the clinician administering the interview based on combined youth- and parent-report.

\section{Spence Children's Anxiety Scale}

(SCAS-C/P, Spence, 1998), child and parent versions were used to assess youth anxiety symptoms. The SCAS 
comprises 38 items rated on a 4-point Likert scale from 0 (never) to 3 (always). Internal consistency for the SCAS in the current sample was $\alpha=0.91$ for youth and $\alpha=0.87$ for parents.

\section{Therapeutic Alliance Scale for Children}

(TASC-C; Shirk \& Saiz 1992; Accurso \& Garland 2015) child version was used to assess alliance in session 3 . The TASC comprises 12 -items scored on a 4-point scale ranging from 1 (not true at all) to 4 (very true). The TASC-C have demonstrated internal consistency $(\alpha=0.88$ to 0.96 ; Accurso \& Garland, 2015; Creed \& Kendall, 2005). Internal consistency for the TASC in the present sample was $\alpha=0.77$.

\section{Quality of the Exposure Component Form}

(QECF, Authors' own) was used to assess exposure quality. The QECF was developed by the authors of the present paper for rating FRIENDS sessions and is an adapted version of The Exposure Session Rating Form (ESRF) developed by Tiwari et al. (2013) for rating Coping Cat-sessions. The ESRF is an observer-rated form. It comprises 15 items covering introductory, preparatory, processing, and closing exposure-related activities (e.g., role-play, reward for effort) and two global items rating overall preparation and processing of exposure. The ESFR can be reliably coded, with reported kappas $>0.81$ for the activity items and ICCs $>0.80$ for the global items (Tiwari et al., 2013). Internal consistency for the ESFR has not been reported (Tiwari et al., 2013). We adapted the ESFR with consent from its developers (i.e., Tiwari \& Kendall). Specifically, items were adapted to fit with descriptions in the FRIENDS manual for the exposure sessions (e.g., use of step plans, fear ratings). The QECF was developed in Norwegian and because items were adapted for a different CBT manual, a backtranslation was not conducted.

The QECF comprises 19 items rated on a 5-point Likert scale from 1 (not at all) to 5 (very much). The QECF covers five main themes (i.e., preparation, actual exposure, post-processing, collaboration/climate, and parent contribution). A final item captures an overall evaluation of the exposure component. Coders also record how many minutes of the session were spent on exposure tasks. For item details including inter-item reliabilities and coder intra-correlations, see Table 1. Only the QECF total and the preparation, post-processing, and parent contribution subscales evidenced sufficient inter-item reliability to be considered separate variables. Therefore, analyses of the actual exposure and collaboration/climate subscales were not conducted.

\section{Procedures}

Parents and youths aged 12 years or older provided written informed consent and assent. Verbal assent was obtained from younger children. The Regional Committee for Ethics in Medical Health Research-West approved the study (\#2011/1004).

Independent observers rated the QECF based on videotapes from randomly selected CBT sessions containing the Step plans component of the FRIENDS manual (i.e., sessions 5 to 10). The QECF raters were two final-year students in a 6-year clinical psychology program. The raters were masked for treatment outcome. The raters were trained with reading materials and an educational presentation of the QECF. Practice sessions (i.e., video sessions not included in the main material) were rated together with an

Table 1 Item mean scores and reliabilities for the quality of the exposure component form

\begin{tabular}{|c|c|c|c|}
\hline & $M$ & $S D$ & ICC \\
\hline \multicolumn{4}{|l|}{$N=68$, based on 118 tapes } \\
\hline Total scale $(\alpha=0.76)$ & 2.2 & 0.4 & $0.92^{\mathrm{a}}$ \\
\hline Preparation $(\alpha=0.62)$ & 1.8 & 0.4 & - \\
\hline Use of psychoeducation & 2.5 & 0.8 & 0.77 \\
\hline Use of step plans as anxiety hierarchy & 2.0 & 0.9 & 0.91 \\
\hline Address gradual difficulty of steps & 1.4 & 0.5 & 0.88 \\
\hline Discuss practical aspects of exposure & 1.9 & 0.8 & 0.84 \\
\hline \multicolumn{4}{|l|}{ Actual exposure $(\alpha=0.05)$} \\
\hline Role play exposure tasks in session & 1.1 & 0.3 & 1.00 \\
\hline Actual exposure tasks in session & 1.1 & 0.4 & 1.00 \\
\hline Evident exposure tasks outside session & 2.2 & 0.9 & 0.97 \\
\hline Post-processing about exposure $(\alpha=0.62)$ & 1.6 & 0.6 & - \\
\hline Discuss non-compliance with exposure & 2.3 & 0.9 & 0.93 \\
\hline Discuss what went well & 1.6 & 0.8 & 0.90 \\
\hline Discuss challenges & 1.4 & 0.7 & 0.97 \\
\hline Discuss how exposure may be done differently & 1.7 & 0.9 & 0.96 \\
\hline Adjust the step plan & 1.4 & 0.8 & 0.97 \\
\hline Collaboration/climate $(\alpha=47)$ & - & - & - \\
\hline Collaboration on exposure & 2.5 & 0.7 & 0.83 \\
\hline Use of reinforcement & 2.5 & 0.9 & 0.96 \\
\hline Youth avoidance $*$ r & 4.4 & 0.8 & 0.93 \\
\hline Youth resistance $* \mathrm{r}$ & 4.8 & 0.6 & 0.93 \\
\hline Parent contribution $(\alpha=0.76)$ & 2.2 & 0.7 & - \\
\hline Parent involved in session exposure & 2.3 & 0.8 & 0.97 \\
\hline Discuss parents' role in exposure tasks & 2.0 & 0.8 & 0.77 \\
\hline \multicolumn{4}{|l|}{ Overall quality of exposure content in session } \\
\hline Overall quality of exposure content in session & 2.3 & 0.7 & 0.96 \\
\hline
\end{tabular}

QECF Quality of the Exposure Component Form, ICC intraclass correlations (oneway random). $* r$ reversed items. ${ }^{a}$ Mean ICC across all items. Mean of subscales only calculated for subscales with acceptable inter-item reliabilities 
experienced clinician who had previously rated another sample of tapes from the same population. After a practice period, each rater was assigned 20 videotapes, which were rated independently. Both raters rated $20 \%$ of these tapes and reliability analyses were conducted to determine interrater agreement. When this was achieved, each rater was randomly assigned another 20 videotapes, which were also rated independently. Subsequently, both raters rated $20 \%$ of these tapes, and additional reliability analyses were conducted. We repeated these steps in blocks of 20 tapes with $20 \%$ double coding until all 118 tapes were coded. The stepwise approach was used to prevent rater drift. Regular meetings between the coders and the first author, an experienced clinician, were held to resolve disagreements. The inter-rater reliability for QECF was calculated using intra-class correlation coefficients (ICCs) using the one-way random effects model (Shrout \& Fleiss, 1979). The following criteria were used to evaluate ICC agreement: good (0.60 to 0.74) and excellent (0.75 to 1.00; Cicchetti, 1994). Coder agreement was excellent (see Table 1).

In the Tiwari trial (2013), observers coded three tapes per participant, from early, mid, and late in treatment, Because the FRIENDS program is shorter than the Coping Cat program (10 versus 14 sessions, respectively), and exposure is included in sessions 5-9 only, we aimed to code two exposure sessions per participant. However, due to resource restrictions, we were only able to code two sessions from 50 of the 68 cases ( $75.8 \%$ of the sample). This means a total of 118 randomly selected sessions were coded from 68 cases. There was no significant difference between the QECF scores of those two sessions (all $p<$ 0.301). Therefore, the mean scores of the two sessions were calculated to represent these participants' scores. As preliminary analyses, we described the amount (i.e., time) of exposure registered and examined if this was related to the other study variables (i.e., pre-treatment variables, outcomes, and alliance). We also examined if there were differences in any of the study variables based on the availability of exposure sessions.

\section{Statistical Analyses}

Analyses were conducted in five main steps. We used SPSS version 20 for the first two steps. First, we conducted preliminary analyses checking differences between included participants and those with missing tapes, therapist variance and data distribution (e.g., normality), exposure duration, and collinearity between variables. Second, we examined Pearson's r-correlations between the main study variables. In the next three steps, we used the equivalent of a hierarchical logistic regression in MPlus version 8 to analyze associations between exposure quality and (a) pretreatment variables; (b) outcomes (i.e., diagnostic recovery, clinical severity change, anxiety symptom change at post-treatment and one-year follow-up, and dropout); (c) child- and therapist-rated alliance (session 3). The 68 youth in the current sample were clustered at the therapist $(n=17)$ and site $(n=7)$ levels. The mean number of participants was 3.8 per therapist (range 1 to 9 ) and 9.4 per site (range 5 to 15 ). Thus, the regression models were adjusted for potential clustering effects due to the nesting of patients within therapists, and therapists within treatment sites (Muthén \& Muthén, 2011). Regression models were logistic for dichotomous variables (i.e., gender, diagnostic outcomes, and dropout) and linear for the other variables.

It is important to note that as we present secondary analyses of already published outcome data (Wergeland et al., 2014). The current study was not designed for these secondary analyses, and power calculation for the main study was based on other research questions (i.e., pre-post effectiveness data). We coded the maximum amount of tapes to capacity, but a potential lack of power needs to be kept in mind when interpreting the findings.

\section{Results}

\section{Preliminary Analyses}

We first compared characteristics between the 68 participants included in the present study and the 23 participants not included due to dropout or missing videotapes. There were no statistically significant differences in demographic data, pretreatment anxiety symptoms, alliance scores, or diagnostic or symptom outcomes (all $p>$ 0.143 ), with one exception. Clinical severity change from pretreatment to post-treatment was larger for included participants compared to non-included participants $(p=0.045)$.

There was very little between-therapist variance in exposure quality $(\mathrm{ICC}=0.02)$. The range of the $\mathrm{QECF}$ total was 1.4 to 3.2 (possible range 1.0 to 5.0 ). The total scale, as well as the reliable subscales (i.e., preparation, post-processing, and parent contribution), were normally distributed (i.e., no skewness values $>1.239$, no kurtosis values $>$ 1.398). Across the 116 sessions coded, the mean duration of exposure was $23 \mathrm{~min}$ per session $(\mathrm{SD}=11 \mathrm{~min}$, range 5 to $60 \mathrm{~min}$ ). The duration was not significantly correlated with outcomes, dropout, or the alliance.

Across all regression models which included the QECF subscales, there were no VIF values $>1.44$ and no tolerance values $<0.69$. Across the same models, there were no predictor eigenvalues $>0.07$ and no condition indices $>16.55$. Thus, our models did not have a problematic level of multicollinearity (Hair et al., 2006). 
Table 2 Correlations between exposure quality variables, age, pre-treatment symptoms, and alliance

\begin{tabular}{lcccccccc}
\hline Variables $(N=68)$ & 1. & 2. & 3. & 4. & 5. & 6. & 7. & 8. \\
\hline 1. Total exposure & - & & & & & & \\
2. Preparation & $0.84^{* *}$ & - & & & & & \\
3. Post-processing & $0.79^{* *}$ & $0.52^{* *}$ & - & & & & \\
4. Parent contribution & $0.65^{* *}$ & $0.42^{* *}$ & $0.39^{* *}$ & - & & & & \\
5. Youth age & -0.21 & -0.06 & -0.11 & $-0.31^{*}$ & - & & \\
6. CSR & -0.02 & 0.09 & -0.03 & -0.06 & 0.03 & - & \\
7. SCAS-C & 0.00 & 0.12 & 0.07 & -0.03 & 0.13 & $0.26^{*}$ & - & \\
8. SCAS-P & 0.06 & 0.11 & 0.08 & -0.05 & 0.00 & 0.09 & $0.27^{*}$ & - \\
9. TASC-C & -0.12 & -0.13 & -0.09 & -0.23 & -0.05 & 0.03 & $0.30^{* *}$ & 0.14 \\
\hline
\end{tabular}

CSR Clinical severity rating of the primary anxiety diagnosis, SCAS Spence Children's Anxiety Scale, $C$ Child, $P$ Parent, TASC Therapeutic Alliance Scale for Children. $* p<0.05$. $* * p<0.001$

\section{Correlations between Variables}

See Table 2 for correlations between main study variables. The exposure components preparation, parent contribution, and post-processing were all significantly related (all $p<$ $0.001)$. Only parent contribution to exposure was significantly related to youth age $(p=0.010)$. The exposure components were not significantly correlated with the other study variables (i.e., anxiety symptoms, clinical severity ratings, alliance).

\section{Are Pre-Treatment Variables Associated with Exposure Quality?}

See Table 3 for an overview of associations between pretreatment variables and exposure quality. In terms of gender, total exposure quality was significantly lower for girls compared to boys, as was the subscale parent contribution to exposure. There was no significant gender difference on the other subscales (all $p>0.054$ ). In terms of age, youth age was significantly and negatively associated with parent contribution to exposure. Thus, there was lower parental contribution to exposure for older youth. Youth age was not associated with any of the other exposure quality variables (all $p>0.145$ ). In terms of the type of anxiety diagnosis (SAD, SOP, GAD), this was not associated with any of the exposure variables (all $p>0.053$ ). In terms of pre-treatment clinical severity, this was not associated with any of the exposure variables (all $p>0.196$ ).

\section{Is Exposure Quality Associated with Outcomes?}

See Table 4 for an overview of associations between exposure variables and outcomes. In terms of diagnostic recovery, logistic regression showed none of the exposure variables were associated with diagnostic recovery at posttreatment (all $p>0.131$ ). However, parent contribution to exposure was significantly associated with loss of all
Table 3 Predicting exposure quality from pre-treatment variables

\begin{tabular}{|c|c|c|c|c|c|}
\hline \multirow{2}{*}{$\begin{array}{l}\text { Exposure } \\
\text { component and } \\
\text { predictors } \\
N=68\end{array}$} & \multirow[b]{2}{*}{ B (SE) } & \multirow[b]{2}{*}{$z$} & \multirow[b]{2}{*}{$p$} & \multicolumn{2}{|c|}{$95 \% \mathrm{CI}$ for $\mathrm{B}$} \\
\hline & & & & Lower & Upper \\
\hline \multicolumn{6}{|l|}{ QECF total } \\
\hline Age & $-0.03(0.02)$ & -1.46 & 0.145 & -0.07 & 0.01 \\
\hline Gender & $-0.15(0.06)^{*}$ & -2.38 & 0.018 & -0.27 & -0.03 \\
\hline Primary $\mathrm{dx}$ SAD & $0.09(0.16)$ & 0.56 & 0.575 & -0.22 & 0.39 \\
\hline Primary dx SOP & $0.05(0.14)$ & 0.37 & 0.711 & -0.22 & 0.32 \\
\hline Clinical severity & $-0.01(0.04)$ & -0.17 & 0.869 & -0.08 & 0.06 \\
\hline \multicolumn{6}{|l|}{ QECF preparation } \\
\hline Age & $-0.03(0.02)$ & -0.12 & 0.906 & -0.05 & 0.04 \\
\hline Gender & $-0.12(0.07)$ & -1.65 & 0.100 & -0.26 & 0.02 \\
\hline Primary $\mathrm{dx}$ SAD & $0.06(0.16)$ & 0.36 & 0.721 & -0.25 & 0.36 \\
\hline Primary dx SOP & $0.03(0.12)$ & 0.29 & 0.771 & -0.20 & 0.26 \\
\hline Clinical severity & $0.03(0.04)$ & 0.81 & 0.418 & -0.05 & 0.12 \\
\hline \multicolumn{6}{|l|}{ QECF post-processing } \\
\hline Age & $-0.01(0.03)$ & -0.54 & 0.592 & -0.06 & 0.04 \\
\hline Gender & $-0.17(0.09)$ & -1.93 & 0.054 & -0.34 & 0.00 \\
\hline Primary $\mathrm{dx}$ SAD & $0.24(0.23)$ & 0.36 & 0.312 & -0.22 & 0.69 \\
\hline Primary dx SOP & $-0.01(0.15)$ & -0.08 & 0.934 & -0.31 & 0.29 \\
\hline Clinical severity & $0.01(0.04)$ & 0.23 & 0.819 & -0.07 & 0.09 \\
\hline \multicolumn{6}{|c|}{ QECF parent contribution } \\
\hline Age & $-0.08(0.03)^{*}$ & -2.25 & 0.024 & -0.14 & -0.01 \\
\hline Gender & $-0.34(0.16)^{*}$ & -2.21 & 0.027 & -0.14 & -0.04 \\
\hline Primary dx SAD & $-0.29(0.15)$ & -1.94 & 0.053 & -0.59 & 0.00 \\
\hline Primary dx SOP & $-0.13(0.11)$ & -1.18 & 0.240 & -0.34 & 0.08 \\
\hline Clinical severity & $-0.08(0.06)$ & -1.29 & 0.196 & -0.19 & 0.04 \\
\hline
\end{tabular}

QECF Quality of the Exposure Component Form. Loglikelihood (LL) $(\mathrm{df})=-534(54)$. Akaike Information Criterion $(\mathrm{AIC})=1176$. Bayesian Information Criterion $(\mathrm{BIC})=1311 . * P<0.05$.

anxiety diagnoses at one-year follow-up. None of the other exposure variables were associated with one-year follow-up outcomes. In terms of clinical severity change, there were no associations with exposure variables at post-treatment 
Table 4 Predicting CBT outcomes from exposure quality variables

\begin{tabular}{|c|c|c|c|c|c|}
\hline \multirow{2}{*}{$\begin{array}{l}\text { Outcome and predictors } \\
N=68\end{array}$} & \multirow[b]{2}{*}{ B/OR (SE) } & \multirow[b]{2}{*}{$z$} & \multirow[b]{2}{*}{$p$} & \multicolumn{2}{|c|}{$95 \% \mathrm{CI}$ for $\mathrm{B} / \mathrm{OR}$} \\
\hline & & & & Lower & Upper \\
\hline \multicolumn{6}{|c|}{ Diagnostic recovery post-treatment } \\
\hline QECF preparation & 0.33 & & 0.316 & 0.04 & 2.91 \\
\hline QECF post-processing & 1.46 & & 0.554 & 0.42 & 5.07 \\
\hline QECF parent contribution & 2.28 & & 0.131 & 0.78 & 6.62 \\
\hline \multicolumn{6}{|c|}{ Diagnostic recovery one-year follow-up } \\
\hline QECF preparation & 0.50 & & 0.253 & 0.15 & 1.67 \\
\hline QECF post-processing & 0.96 & & 0.937 & 0.31 & 2.93 \\
\hline QECF parent contribution & $3.24 *$ & & 0.038 & 1.07 & 9.82 \\
\hline \multicolumn{6}{|l|}{ Clinical severity post-treatment } \\
\hline QECF preparation & $-0.57(1.73)$ & -0.33 & 0.742 & -3.95 & 2.82 \\
\hline QECF post-processing & $-0.22(0.94)$ & -0.23 & 0.817 & -2.05 & 1.62 \\
\hline QECF parent contribution & $0.74(0.52)$ & 1.44 & 0.150 & -0.27 & 1.75 \\
\hline \multicolumn{6}{|c|}{ Clinical severity one-year follow-up } \\
\hline QECF preparation & $-0.81(0.77)$ & -1.05 & 0.292 & -2.33 & 0.70 \\
\hline QECF post-processing & $-0.65(0.76)$ & -0.86 & 0.390 & -2.15 & 0.84 \\
\hline QECF parent contribution & $1.63(0.49)^{*}$ & 3.33 & 0.001 & 0.67 & 2.58 \\
\hline \multicolumn{6}{|c|}{ Anxiety symptoms post-treatment } \\
\hline QECF preparation & $-0.92(7.34)$ & -0.13 & 0.901 & -15.31 & 13.48 \\
\hline QECF post-processing & $-3.10(5.13)$ & -0.60 & 0.546 & -13.15 & 6.95 \\
\hline QECF parent contribution & $4.26(3.32)$ & 1.28 & 0.199 & -2.25 & 10.77 \\
\hline \multicolumn{6}{|c|}{ Anxiety symptoms one-year follow-up } \\
\hline QECF preparation & $-3.74(6.80)$ & -0.55 & 0.583 & -17.06 & 9.59 \\
\hline QECF post-processing & $-3.71(3.01)$ & -1.21 & 0.225 & -9.70 & 2.28 \\
\hline QECF parent contribution & $0.24(3.58)$ & 0.07 & 0.947 & -6.77 & 7.25 \\
\hline
\end{tabular}

QECF Quality of the Exposure Component Form. Clinical severity models: Loglikelihood (LL) (df) $=-493$ (20). Akaike Information Criterion $(A I C)=1025$. Bayesian Information Criterion $(B I C)=1073$. Anxiety symptom models: Loglikelihood $(\mathrm{LL})(\mathrm{df})=-1153(35) . \mathrm{AIC}=2376 . \mathrm{BIC}=2459 . * P<0.05$. (all $p>0.150$ ). However, more parent contribution to exposure predicted a larger reduction in clinical severity at the one-year follow-up. In terms of anxiety symptom change, there were no associations with exposure variables at any measurement point (all $p>0.199$ ). Finally, in terms of dropout, $t$-tests showed total exposure quality and exposure preparation was significantly lower for the two cases who dropped out (both $p<0.05$ ), with effect size differences $d=2.27$ for total exposure and $d=2.14$ for preparation. It is important to note that exposure variables were only rated for two dropout cases. This is because all other dropouts from the ICBT trial, an additional 13 cases, had dropped out before the exposure component was introduced (i.e., before session 6).

\section{Is Exposure Quality Associated with the Alliance?}

A multiple regression model predicting youth-rated alliance from the exposure variables showed none of the predictors were significant (all $p>0.114$ ). See Table 5.

\section{Discussion}

We examined exposure quality in an ICBT effectiveness trial for youth with anxiety disorders. Our first aim was to examine if pre-treatment variables were associated with exposure quality. Due to limited previous data, we explored this research question openly. We found that total exposure quality and parent contribution to exposure was lower for girls than for boys. There is evidence that parents and other adults have different expectations of boys and girls, and that boys are more likely than girls to be engaged in rough-andtumble play, be given fewer physical boundaries, and be more rewarded for physical bravery (see Morawska, 2020, for review). Such gender stereotypes may come into play when adults (therapists and parents) engage in exposure tasks with youth and be associated with the gender difference found in the current study. Furthermore, because girls tend to have more anxiety (disorders and symptoms) than boys (e.g., Arendt et al., 2014; Beesdo et al., 2009; Spence et al., 2003), both therapists and parents may have been 
Table 5 Predicting alliance from exposure quality variables

\begin{tabular}{lllllll}
\hline $\begin{array}{l}\text { Outcome and } \\
\text { predictors }\end{array}$ & & & & \multicolumn{2}{c}{$95 \%$ CI for B } \\
\cline { 5 - 6 }$N=68$ & B (SE) & $z$ & $p$ & Lower & Upper \\
\hline Child-rated alliance & & & & & & \\
QECF Total & $2.52(3.85)$ & 0.65 & 0.513 & -5.03 & 10.07 \\
QECF preparation & $-1.70(2.25)$ & -0.75 & 0.451 & -6.11 & 2.72 \\
$\begin{array}{l}\text { QECF post- } \\
\text { processing }\end{array}$ & $-0.91(1.61)$ & -0.57 & 0.571 & -4.06 & 2.24 \\
$\begin{array}{l}\text { QECF parent } \\
\text { contribution }\end{array}$ & $0.78(0.81)$ & 0.96 & 0.338 & -0.82 & 2.38 \\
$\begin{array}{l}\text { Therapist-rated alliance } \\
\text { QECF Total }\end{array}$ & & & & & & \\
$\begin{array}{l}\text { QECF preparation } \\
\text { QECF post- }\end{array}$ & $-4.65(9.25)$ & 0.82 & 0.408 & -10.48 & 25.78 \\
processing & $-1.84(3.20)$ & -1.12 & 0.263 & -12.93 & 3.53 \\
$\begin{array}{l}\text { QECF parent } \\
\text { contribution }\end{array}$ & $-3.32(2.11)$ & -0.47 & 0.638 & -9.50 & 5.82 \\
\end{tabular}

QECF Quality of the Exposure Component Form. Loglikelihood (LL) $(\mathrm{df})=-456(27)$. Akaike Information Criterion $(\mathrm{AIC})=967$. Bayesian Information Criterion $(\mathrm{BIC})=1032$

more reluctant to engage girls in exposure tasks that were considered too demanding based on the youth's anxiety level. In terms of age, parental contribution to exposure was lower for older youth. This may be related to normal developmental processes, during which youth become increasingly autonomous with age (Daddis, 2011).

Our age and gender-related findings are in some contrast to Tiwari et al. (2013), who found no age or gender effects for exposure quality. However, except total exposure being lower for girls than boys, the gender and age effects identified in the current study applied to parent contribution to exposure. Parent exposure was not included as a variable in Tiwari et al. (2013). This means the findings are not directly comparable. Nevertheless, in terms of age, our study had a slightly wider age range than Tiwari et al., with 8 to 16 years versus 7 to 13 in Tiwari et al. The older youth in our sample may have driven the age effect in our study. In terms of the gender difference, the gender balance was slightly more even in the current study than in Tiwari et al. (2013), who had $62.3 \%$ males. This may have enhanced our power to detect effects. Further studies are needed to examine if the age and gender effects identified herein apply to other samples.

We found no influence on exposure quality based on primary diagnosis and/or clinical severity at pre-treatment. This is in some contrast to Tiwari et al. (2013), who found support for comorbid anxiety disorders predicting exposure preparedness. The low extent of exposure in the FRIENDS program versus the Coping Cat program may have impaired our statistical power to uncover small effects of clinical severity on exposure quality in our sample. Future studies are needed to determine the role of initial anxiety levels for exposure quality. On the one hand, high fear may lead to more exposure. On the other hand, therapists and parents may be reluctant to expose youth with high fear. This may manifest through few exposure tasks and/or unambitious exposure steps (e.g., practicing exposure to situations the youth does not fear that much). More empirical data on this issue are needed.

Our second aim was to examine associations between exposure quality and outcomes. We found that that parental contribution to exposure predicted loss of all anxiety diagnoses, and a larger reduction in clinical severity, at one-year follow-up. This effect was not evident for post-treatment outcomes. This finding is important, as it suggests that the effects of exposure quality on outcomes may not come into play immediately following the end of treatment, but rather influence how youth (and parents) continue to work on therapeutic tasks (and improve) in the months after CBT has finished. FRIENDS is a 10-session program, and the need to keep practicing tasks learned is emphasized in the final sessions. Our finding may reflect that parents who contributed to exposure during treatment may have continued to do so also in the time after the CBT program had finished, increasing the odds for their children to lose all anxiety diagnoses one year post-treatment. Total exposure quality and exposure preparation were higher for treatment completers than for dropouts, with large effect size differences. However, this finding should be interpreted with much caution since only two cases who dropped out had tapes available for QECF coding.

An important question regarding our findings is whether parental contribution to exposure is a proxy for general parental involvement in treatment. Several review studies have shown parental involvement does not enhance treatment outcomes for child anxiety disorders (e.g., Reynolds et al., 2012; Silverman et al., 2008). However, a metaanalytic study that combined data from several trials showed that parental involvement conditions with emphasis on transfer of control from the therapist to parents and parental contingency management (i.e., reward) for exposure to anxiety-provoking situations were associated with better post-treatment and long-term outcomes than other or no parental involvement conditions (Manassis et al., 2014). In the current study, parental involvement was standardized to $15 \mathrm{~min}$ at the end of each session plus two separate parent meetings. We do not have data on the quality of this parental involvement, beyond the current data on parent contribution to exposure. Our finding, alongside the findings of Manassis et al. (2014), indicates parental involvement in exposure tasks may be a particularly relevant element of parental involvement in CBT outcomes for youth anxiety.

Another important possibility to consider is that the parent contribution to exposure findings may be due to 
confounding factors. One such potential factor is parent accommodation, i.e., parental routines and behaviors meant to alleviate youth anxiety symptoms. Parent accommodation is a well-documented maintenance factor for youth anxiety (Kagan et al., 2016; Zilcha-Mano et al., 2021). Examples of parental accommodation are allowing schoolphobic youth to stay home from school and speaking for socially anxious youth. There is a particular link between accommodation and exposure via the concept of avoidance, another anxiety maintenance factor. That is, whereas one of the problems with accommodation is that it promotes avoidance (Ginsburg et al., 2004). One of the main goals of exposure is to avoid avoidance. It is possible, albeit we do not have the data to examine this, that parents who contributed more to exposure during treatment learned and understood the rationale for exposing children to feared stimuli, and thus accommodated less post-treatment. The effects of parental contribution were demonstrated at oneyear follow-up only, and not as post-treatment. This suggests that lengthier processes, such as changing accommodation behaviors, may have played a confounding part in our findings.

Our third aim was to examine associations between exposure quality and alliance. We found that exposure quality did not predict alliance quality. On the one hand, it can be considered positive news that alliance and exposure are unrelated, given community therapists' concerns that uncomfortable exposure tasks may impair alliance quality (Peterman et al., 2015). Our findings are also in line with previous findings that alliance is not negatively impacted by exposure tasks in CBT for youth with anxiety disorders (Kendall et al., 2009). However, given considerable documentation that alliance and exposure, when regarded separately, are related to outcomes (Abramowitz et al., 2011; McLeod, 2011), one may expect exposure and alliance to also be linked as mechanisms of change in CBT. Indeed, we expected higher exposure quality to be associated with a higher alliance, given findings from an efficacy trial that showed that the alliance continued to enhance after exposure sessions were imitated (Kendall et al., 2009). A trusting relationship between youths and therapists may make exposure more successful. Our zero findings may be related to the fact that alliance was only measured once, and early in treatment (i.e., session 3 of 10). An alliance slope informed by multiple measurement points may have revealed potential associations. Furthermore, the alliance measure used in the current study was characterized by high scores and limited variance, like in many alliance studies (McLeod, 2011). This may have prevented us from detecting smaller associations.

Relatedly, across the aims, it is important to note that the overall level of exposure observed was low. This may reflect that therapists did little exposure, which is in line with other findings from community clinics (Whiteside et al., 2016). The FRIENDS program contains less insession exposure and fewer overall sessions than the Coping Cat program, which may help explain why observed exposure quality was low, and the items restricted. It is also important to consider the study findings in terms of potential power to detect effects. We coded at least one session from all participants with available tapes, and our sample size was slightly larger than Tiwari et al. (2013), who found small but significant effects between exposure components and clinician-rated outcomes. Nevertheless, our study may have been underpowered to identify small effects on other outcomes. Future studies should observe exposure in larger samples and examine relations with outcomes before clearer conclusions can be made. This applies to the zero-findings in particular, which are questionable due to the sample size.

The exposure rating form used in the current study was based on a form developed for the Coping Cat (Tiwari et al., 2013), but adapted for the FRIENDS program. Coders observed sessions in which the FRIENDS manual contains exposure tasks. In the FRIENDS program, these tasks are linked to the core concept of coping step plans, in which youth, in collaboration with the therapist and their parent(s), work on setting gradual goals for how the youth should approach and not avoid feared situations. A simplified example would be to break down the task of speaking in front of the class into the following steps: (a) prepare the speech, (b) practice with parents, (c) practice with a small group of friends; (d) give the speech in front of the class. Importantly, the exposure task in itself (speaking) is not done in isolation from other CBT components. That is, the youth is encouraged to identify and rate emotions associated with the task and to identify helpful and unhelpful thoughts related to the task. The reasoning is that emotional regulation (e.g., breathing exercises) and cognitive restructuring (e.g., thinking "I may be able to do this" rather than "This will be a disaster"), both techniques the youth has learned in previous sessions, are meant to help the youth manage the exposure tasks. An explicit aim of the FRIENDS program is that the youth learn to integrate the emotional, cognitive, and behavioral components to deal better with their anxiety. Relevant for the aim of the current study, however, this also means that the exposure component - in terms of quality, amount, and content-is not necessarily distinguishable from other CBT components. On the one hand, this represents a certain paradox in light of the aim to disentangle effective CBT elements. On the other hand, however, it also reflects that exposure is not done in isolation without preparation and post-processing that considers how the youth thinks and feels about exposure. This is in line with the process stages of exposure described earlier by experts in the field (Seligman \& Ollendick, 2011). 


\section{Strengths and Limitations}

The current study is the first to observe exposure quality in the FRIENDS intervention. By rating videotapes, more insight is achieved concerning what goes on in therapy, compared to other research designs (e.g., self-report or interviews of therapists and clients). Additional strengths include the use of a manual-based CBT program in a community setting, with nonspecialist therapists and regularly referred clients. These factors enhance the ecological validity of the trial. However, the study also has limitations. First, although we rated the largest number of tapes to coder capacity, the sample size may have left us underpowered to detect small effects. Second, the preparation and post-processing subscales used in the analyses had internal consistencies that can be considered questionable (i.e., $\alpha=$ 0.62). However, these alpha levels need to be seen in light of the low number of items per subscale, (i.e., four and five items, respectively) which may artificially reduce alphas (Cortina, 1993). Given the significant overlap with the other QECF subscales and the total scale and the fact that the QECF is a newly developed observation-based measure, we consider the preparation and post-processing subscales to represent potentially reliable exposure dimensions. However, the questionable internal consistency levels for these scales may have contributed to their lack of predictive validity, and further investigation of these subscales is needed. Third, the data were possibly weakened by the fact that only one to two out of ten sessions contributed to the scores on the QECF. The sessions were selected as they are the main sessions where the concept of exposure is introduced and worked on according to the manual (Barrett, 2004). We cannot know what happened outside of therapy and if or how the feared situations were confronted as homework, as we were only able to rate the content of the 60-minute sessions. Fourth, both the youth and therapist samples were dominantly European-White, and findings may not apply to participants of other ethnic backgrounds. Finally, the findings cannot be generalized to youth treated with other treatment programs and/or in other settings.

\section{Clinical Implications}

The current study has several implications. The first is related to the findings concerning pre-treatment factors. Therapists and parents may need to be particularly aware of enhancing exposure with girls and older youth. Second, related to the outcome findings, a main implication of the current study is that parent contribution to exposure may contribute to the increased likelihood of diagnostic recovery and clinical improvement in the year after CBT. This means clinicians should emphasize the role of parents in continuing to assist their children with anxiety problems in conducting exposure tasks during treatment, and also encourage the continuation of this when CBT comes to an end.
However, it is important to note that other exposure domains were not related to treatment outcome and that exposure did not predict post-treatment outcomes. This finding is of clinical importance, considering the theoretical rationale of exposure in CBT and a large amount of literature that stresses the importance of doing exposure (e.g., Beidel et al., 2000; Chorpita et al., 2002; Kendall et al., 2005). Increasing the amount of in-session exposure should be considered in the future implementation of the FRIENDS program in treatment settings. Third, clinicians should be aware that the alliance is not negatively impacted by conducting exposure in CBT.

\section{Conclusion}

The pre-treatment variables female gender and older youth age was associated with poorer exposure quality. Parent contribution to exposure predicted better long-term outcomes, indicating that this could be an important treatment component to enhance. The alliance was not negatively affected by exposure. This means clinicians should strive to enhance the exposure component when delivering CBT to youth with anxiety.

Funding The project was funded by the Western Norway Health Authorities (project numbers 91136 and 911253). Open access funding provided by University of Oslo (incl Oslo University Hospital).

\section{Compliance with Ethical Standards}

Conflict of Interest The authors declare no competing interests.

Research Involving Human Participants and/or Animals The research involved humans aged 8 years and older. The study was approved by the Regional Committee for Medical and Health Research Ethics Western Norway. We declare that principles of research ethics involving children were followed in all parts of the study.

Informed Consent All participants provided informed consent. Parents and children $>12$ years provided written informed consent. Participants aged 8-12 years provided verbal assent and were only included if parents had provided written consent.

Publisher's note Springer Nature remains neutral with regard to jurisdictional claims in published maps and institutional affiliations.

Open Access This article is licensed under a Creative Commons Attribution 4.0 International License, which permits use, sharing, adaptation, distribution and reproduction in any medium or format, as long as you give appropriate credit to the original author(s) and the source, provide a link to the Creative Commons license, and indicate if changes were made. The images or other third party material in this article are included in the article's Creative Commons license, unless indicated otherwise in a credit line to the material. If material is not included in the article's Creative Commons license and your intended use is not permitted by statutory regulation or exceeds the permitted use, you will need to obtain permission directly from the copyright 
holder. To view a copy of this license, visit http://creativecommons. org/licenses/by/4.0/.

\section{References}

Abramowitz, J. S., Deacon, B. J., \& Whiteside, S. P. (2011). Exposure therapy for anxiety: Principles and practice. New York, NY: Guilford Press.

Accurso, E. C., \& Garland, A. F. (2015). Child, caregiver, and therapist perspectives on therapeutic alliance in usual care child psychotherapy. Psychological Assessment, 27(1), 347-352. https://doi.org/10.1037/pas0000031.

Ale, C. M., McCarthy, D. M., Rothschild, L. M., \& Whiteside, S. P. H. (2015). Components of cognitive behavioral therapy related to outcome in childhood anxiety disorders. Clinical Child and Family Psychology Review, 18(3), 240-251. https://doi.org/10. 1007/s10567-015-0184-8.

Arendt, K., Hougaard, E., \& Thastum, M. (2014). Psychometric properties of the child and parent versions of Spence Children's Anxiety Scale in a Danish community and clinical sample. Journal of Anxiety Disorders, 28(8), 947-956. https://doi.org/10. 1016/j.janxdis.2014.09.021.

Barrett, P. M 2004). Friends for life-Group leader's manual. 4th ed. Brisbane: Australian Academic Press.

Barrett, P. M., \& Ryan, S. (2004). Friends for life: For children. Australian Academic Press.

Beidel, D. C., Turner, S. M., \& Morris, T. L. (2000). Behavioral treatment of childhood social phobia. Journal of Consulting and Clinical Psychology, 68(6), 1072-1080. https://doi.org/10.1037/ 0022-006X.68.6.1072.

Beesdo, K., Knappe, S., \& Pine, D. S. (2009). Anxiety and anxiety disorders in children and adolescents: Developmental issues and implications for DSM-V. Psychiatric Clinics of North America, 32(3), 483 https://doi.org/10.1016/j.psc.2009.06.002.

Bjaastad, J. F., Haugland, B. S. M., Fjermestad, K. W., Torsheim, T., Havik, O. E., Heiervang, E. R., \& Ost, L. G. (2016). Competence and Adherence Scale for Cognitive Behavioral Therapy (CASCBT) for anxiety disorders in youth: Psychometric properties. Psychological Assessment, 28(8), 908-916. https://doi.org/10. 1037/pas0000230.

Briesch, A. M., Hagermoser Sanetti, L. M., \& Briesch, J. M. (2010). Reducing the prevalence of anxiety in children and adolescents: An evaluation of the evidence base for the FRIENDS for life program. School Mental Health, 24, 155-165. https://doi.org/10. 1007/s12310-010-9042-5.

Chorpita, B. F., Yim, L. M., Donkervoet, J. C., Arensdorf, A., Amundsen, M. J., McGee, C., Serrano, A., Yates, A., Burns, J. A., \& Morelli, P. (2002). Toward large-scale implementation of empirically supported treatments for children: A review and observations by the Hawaii Empirical Basis to Services Task Force. Clinical Psychology: Science and Practice, 9(2), 165-190. https://doi.org/10.1111/j.1468-2850.2002.tb00504.x.

Cicchetti, D. V. (1994). Guidelines, criteria, and rules of thumb for evaluating normed and standardized assessment instruments in psychology. Psychological Assessment, 6(4), 284-290. https:// doi.org/10.1037/1040-3590.6.4.284.

Cortina, J. M. (1993). What is coefficient alpha-An examination of theory and applications. Journal of Applied Psychology, 78(1), 98-104. https://doi.org/10.1037/0021-9010.78.1.98.

Creed, T. A., \& Kendall, P. C. (2005). Therapist alliance-building behavior within a cognitive-behavioral treatment for anxiety in youth. Journal of Consulting and Clinical Psychology, 73(3), 498-505. https://doi.org/10.1037/0022-006X.73.3.498.
Currie, C., Molcho, M., Boyce, W., Holstein, B., Torsheim, T., \& Richter, M. (2008). Researching health inequalities in adolescents: The development of the Health Behaviour in School-Aged Children (HBSC) Family Affluence Scale. Social Science \& Medicine, 66(6), 1429-1436. https://doi.org/10.1016/j.socscimed. 2007.11.024.

Daddis, C. (2011). Desire for increased autonomy and adolescents' perceptions of peer autonomy: "Everyone else can; why can't I?". Child Development, 82: 1310-1326. https://doi.org/10.1111/j. 1467-8624.2011.01587.x.

Deacon, B. J., \& Abramowitz, J. S. (2004). Cognitive and behavioral treatments for anxiety disorders: A review of meta-analytic findings. Journal of Clinical Psychology, 60(4), 429-441. https:// doi.org/10.1002/jclp.10255.

Digiuseppe, R., Linscott, J., \& Jilton, R. (1996). Developing the therapeutic alliance in child- adolescent psychotherapy. Applied and Preventive Psychology, 5(2), 85-100. https://doi.org/10. 1016/S0962-1849(96)80002-3.

Ginsburg, G. S., Siqueland, L., Masia-Warner, C., \& Hedtke, K. A. (2004). Anxiety-disorders in children: Family matters. Cognitive and Behavioral Practice, 11(1), 28-43. https://doi.org/10.1016/ s1077-7229(04)80005-1.

Goodman, R., Ford, T., Richards, H., Gatward, R., \& Meltzer, H. (2000). The Development And Well-being Assessment: Description and initial validation of an integrated assessment of child and adolescent psychopathology. Journal of Child Psychology and Psychiatry, 41(5), 645-655. PMID:10946756.

Gryczkowski, M. R., Tiede, M. S., Dammann, J. E., Jacobsen, A. B., Hale, L. R., \& Whiteside, S. P. (2013). The timing of exposure in clinic-based treatment for childhood anxiety disorders. Behavior Modification, 37(1), 113-127. https://doi.org/10.1177/ 0145445512456546.

Hair, J. F., Black, W. C., Babin, B. J., Anderson, R. E., \& Tatham, R. L. (2006). Multivariate Data Analysis. Upper Saddle River, NJ: Pearson Prentice Hall.

Hedtke, K. A., Kendall, P. C., \& Tiwari, S. (2009). Safety-seeking and coping behavior during exposure tasks with anxious youth. Journal of Clinical Child and Adolescent Psychology, 38(1), 1-15. https://doi.org/10.1080/15374410802581055.

Hipol, L. J., \& Deacon, B. J. (2013). Dissemination of evidence-based practices for anxiety disorders in Wyoming: A survey of practicing psychotherapists. Behavior Modification, 37(2), 170-188. https://doi.org/10.1177/0145445512458794.

Kagan, E. R., Peterman, J. S., Carper, M. M., \& Kendall, P. C. (2016). Accommodation and treatment of anxious youth. Depression and Anxiety, 33(9), 840-847. https://doi.org/10.1002/da.22520.

Kendall, P. C., Comer, J. S., Marker, C. D., Creed, T. A., Puliafico, A. C., Hughes, A. A., Martin, E. D., Suveg, C., \& Hudson, J. (2009). In-session exposure tasks and therapeutic alliance across the treatment of childhood anxiety disorders. Journal of Consulting and Clinical Psychology, 77(3), 517-525. https://doi.org/10. 1037/a0013686.

Kendall, P. C., \& Hedtke, K. (2006). Cognitive-Behavioral Therapy for Anxious Children: Therapist Manual. Ardmore, PA: Workbook Publishing.

Kendall, P. C., Robin, J. A., Hedtke, K. A., Suveg, C., FlannerySchroeder, E., \& Gosch, E. A. (2005). Considering CBT with anxious youth? Think exposures. Cognitive and Behavioral Practice, 12(1), 136-148. https://doi.org/10.1016/S1077-7229(05)80048-3.

Liber, J. M., Van Widenfelt, B. M., Utens, E., Ferdinand, R. F., Van der Leeden, A. J. M., Van Gastel, W., \& Treffers, P. D. A. (2008). No differences between group versus individual treatment of childhood anxiety disorders in a randomised clinical trial. Journal of Child Psychology and Psychiatry, 49(8), 886-893. https://doi.org/10.1111/j.1469-7610.2008.01877.x. 
Lowry-Webster, H. M., Barrett, P. M., \& Lock, S. (2003). A universal prevention trial of anxiety symptomology during childhood: Results at 1-year follow-up. Behaviour Change, 20, 25-43. https://doi.org/10.1375/bech.18.1.36.

Manassis, K., Lee, T. C., Bennett, K., Zhao, X. Y., Mendlowitz, S., Duda, S., Saini, M., Wilansky, P., Baer, S., Barrett, P., Bodden, D., Cobham, V. E., Dadds, M. R., Flannery-Schroeder, E., Ginsburg, G., Heyne, D., Hudson, J. L., Kendall, P. C., Liber, J., \& Wood, J. J. (2014). Types of parental involvement in CBT with anxious youth: A preliminary meta-analysis. Journal of Consulting and Clinical Psychology, 82(6), 1163-1172. https://doi. org/10.1037/a0036969.

McLeod, B. D.(2011). Relation of the alliance with outcomes in youth psychotherapy: A meta-analysis. Clinical Psychology Review, 31 (4), 603-616. https://doi.org/10.1016/j.cpr.2011.02.001.

Morawska, A. (2020). The effects of gendered parenting on child development outcomes: A systematic review. Clinical Child and Family Psychology Review, 23(4), 553-576. https://doi.org/10. 1007/s10567-020-00321-5.

Muthén, L. K., \& Muthén, B. O. (2011). Mplus User's Guide. 6th Edition. Los Angeles, CA: Muthén \& Muthén.

Olatunji, B. O., Cisler, J. M., \& Deacon, B. J. (2010). Efficacy of cognitive behavioral therapy for anxiety disorders: A review of meta-analytic findings. Psychiatric Clinics of North America, 33 (3), 557-577. https://doi.org/10.1016/j.psc.2010.04.002.

Peris, T. S., Caporino, N. E., O'Rourke, S., Kendall, P. C., Walkup, J. T., Albano, A. M., Bergman, R. L., McCracken, J. T., Birmaher, B., Ginsburg, G. S., Sakolsky, D., Piacentini, J., \& Compton, S. N. (2017). Therapist-reported features of exposure tasks that predict differential treatment outcomes for youth with anxiety. Journal of the American Academy of Child \& Adolescent Psychiatry, 56(12), 1043-1052. https://doi.org/10.1016/j.jaac.2017. 10.001 .

Peterman, J. S., Carper, M. M., \& Kendall, P. C. (2016). Testing the habituation-based model of exposures for child and adolescent anxiety. Journal of Clinical Child and Adolescent Psychology, 1-11. https://doi.org/10.1080/15374416.2016.1163707.

Peterman, J. S., Read, K. L., Wei, C., \& Kendall, P. C. (2015). The art of exposure: Putting science into practice. Cognitive and Behavioral Practice, 22(3), 379-392. https://doi.org/10.1016/j.cbpra. 2014.02.003.

Plaisted, H., Waite, P., Gordon, K., \& Creswell, C. (2021). Optimising exposure for children and adolescents with anxiety, OCD and PTSD: A systematic review. Clinical Child and Family Psychology Review, 24(2), 348-369. https://doi.org/10.1007/s10567020-00335-z.

Reynolds, S., Wilson, C., Austin, J., \& Hooper, L. (2012). Effects of psychotherapy for anxiety in children and adolescents: A metaanalytic review. Clinical Psychology Review, 32(4), 251-262. https://doi.org/10.1016/j.cpr.2012.01.005.

Seligman, L. D., \& Ollendick, T. H. (2011). Cognitive-behavioral therapy for anxiety disorders in youth. Child and Adolescent Psychiatric Clinics of North America, 20(2), 217-238. https://doi. org/10.1016/j.chc.2011.01.003.

Shirk, S. R., \& Saiz, C. C. (1992). Clinical, empirical, and developmental perspectives on the therapeutic relationship in child- psychotherapy. Development and Psychopathology, 4(4), 713-728. https://doi.org/10.1017/s0954579400004946.

Shortt, A. L., Barrett, P. M., \& Fox, T. L. (2001). Evaluating the FRIENDS program: A cognitive-behavioral group treatment for anxious children and their parents. Journal of Clinical Child Psychology, 30(4), 525-535. https://doi.org/10.1207/ S15374424JCCP3004_09.

Shrout, P. E., \& Fleiss, J. L. (1979). Intraclass correlations: uses in assessing rater reliability. Psychological Bulletin, 86(2), 420-428. https://doi.org/10.1037/0033-2909.86.2.420.

Silverman, W. K., \& Albano, A. M. (1996). The Anxiety Disorders Interview Schedule For Children and Parents (ADIS-C/P). Albany, NY: Greywind Publications.

Silverman, W. K., Pina, A. A., \& Viswesvaran, C. (2008). Evidencebased psychosocial treatments for phobic and anxiety disorders in children and adolescents. Journal of Clinical Child and Adolescent Psychology, 37(1), 105-130. https://doi.org/10.1080/ 15374410701817907.

Spence, S. H. (1998). A measure of anxiety symptoms among children. Behaviour Research and Therapy, 36(5), 545-566. https:// doi.org/10.1016/s0005-7967(98)00034-5.

Spence, S. H., Barrett, P. M., \& Turner, C. M. (2003). Psychometric properties of the Spence Children's Anxiety Scale with young adolescents. Journal of Anxiety Disorders, 17(6), 605-625. https://doi.org/10.1016/S0887-6185(02)00236-0.

Tiwari, S., Kendall, P. C., Hoff, A. L., Harrison, J. P., \& Fizur, P. (2013). Characteristics of exposure sessions as predictors of treatment response in anxious youth. Journal of Clinical Child \& Adolescent Psychology, 42(1), 34-43. https://doi.org/10.1080/ 15374416.2012.738454.

Wergeland, G. J. H., Fjermestad, K. W., Marin, C. E., Haugland, B. S. M., Bjaastad, J. F., Oeding, K., Bjelland, I., Silverman, W. K., Ost, L.-G., Havik, O. E., \& Heiervang, E. R. (2014). An effectiveness study of individual vs. group cognitive behavioral therapy for anxiety disorders in youth. Behaviour Research and Therapy, 57, 1-12. https://doi.org/10.1016/j.brat.2014.03.007.

Wergeland, G. J. H., Fjermestad, K. W., Marin, C. E., Haugland, B. S. M., Silverman, W. K., Ost, L.-G., Havik, O. E., \& Heiervang, E. R. (2015). Predictors of dropout from community clinic child CBT for anxiety disorders. Journal of Anxiety Disorders, 31, 1-10. https://doi.org/10.1016/j.janxdis.2015.01.004.

Wergeland, G. J. H., Riise, E. N., \& Öst, L.-G. (2020). Cognitive behavior therapy for internalizing disorders in children and adolescents in routine clinical care: A systematic review and metaanalysis. Clinical Psychology Review, 83, 101918 https://doi.org/ 10.1016/j.cpr.2020.101918.

Whiteside, S. P. H., Deacon, B. J., Benito, K., \& Stewart, E. (2016). Factors associated with practitioners' use of exposure therapy for childhood anxiety disorders. Journal of Anxiety Disorders, 40, 29-36. https://doi.org/10.1016/j.janxdis.2016.04.001.

Zilcha-Mano, S., Shimshoni, Y., Silverman, W. K., \& Lebowitz, E. R. (2021). Parent-child agreement on family accommodation differentially predicts outcomes of child-based and parent-based child anxiety treatment. Journal of Clinical Child and Adolescent Psychology, 50(3), 427-439. https://doi.org/10.1080/15374416. 2020.1756300 . 